University of Wollongong

Research Online

Faculty of Engineering and Information

Faculty of Engineering and Information

Sciences - Papers: Part A

Sciences

$1-1-2015$

\title{
A sacrificial-layer approach to fabricate polysulfone support for forward osmosis thin-film composite membranes with reduced internal concentration polarisation
}

\author{
Peipei Xiao \\ Chinese Academy of Sciences \\ Long D. Nghiem \\ University of Wollongong, longn@uow.edu.au \\ Yong Yin \\ Chinese Academy of Sciences \\ Xue-Mei Li \\ Chinese Academy of Sciences \\ Mengxi Zhang \\ Chinese Academy of Sciences
}

See next page for additional authors

Follow this and additional works at: https://ro.uow.edu.au/eispapers

Part of the Engineering Commons, and the Science and Technology Studies Commons

Research Online is the open access institutional repository for the University of Wollongong. For further information contact the UOW Library: research-pubs@uow.edu.au 


\title{
A sacrificial-layer approach to fabricate polysulfone support for forward osmosis thin-film composite membranes with reduced internal concentration polarisation
}

\author{
Abstract \\ This study demonstrates a sacrificial-layer approach by co-casting, which is the simultaneous casting of \\ two layers, to prepare a polysulfone support (denoted as PSfco) layer with open bottom surface \\ morphology for fabricating thin-film composite forward osmosis (FO) membranes. In the co-casting \\ process, polyetherimide (PEI), used as the sacrificial layer, was co-cast beneath the PSf layer. After the \\ PEI layer was peeled off, PSfco was yielded with an open-bottom structure. Results showed that under the \\ same operating condition, the FO membrane prepared by co-casting (denoted as PSfco-TFC) \\ demonstrated a $10 \%$ higher water flux using $0.5 \mathrm{M} \mathrm{NaCl}$ draw solution and $30 \%$ higher water flux using 4 \\ $\mathrm{M} \mathrm{NaCl}$ draw solution in the AL-FS mode in comparison to membranes prepared in a single layer casting \\ technique (denoted as PSfs-TFC). The PSfco-TFC exhibits a lower average structural parameter (S, 167 \\ $\mu \mathrm{m})$ than that of the PSfs-TFC $(241 \mu \mathrm{m})$, while the water and salt permeability coefficients of both \\ membranes are similar. Results reported here demonstrate that the co-casting technique can be used to \\ fabricate FO membranes with significantly improved performance compared to the conventional \\ approach. \\ Disciplines \\ Engineering | Science and Technology Studies

\section{Publication Details} \\ Xiao, P., Nghiem, L., Yin, Y., Li, X., Zhang, M., Chen, G., Song, J. \& He, T. (2015). A sacrificial-layer approach \\ to fabricate polysulfone support for forward osmosis thin-film composite membranes with reduced \\ internal concentration polarisation. Journal of Membrane Science, 481 106-114.
}

\section{Authors}

Peipei Xiao, Long D. Nghiem, Yong Yin, Xue-Mei Li, Mengxi Zhang, Gang Chen, Jianfeng Song, and Tao He 


\title{
A Sacrificial-layer Approach to Fabricate Polysulf one Support for Forward Osmosis Thin-film Composite Membranes with Reduced Internal Concentration Polarisation
}

\author{
Peipei Xiao ${ }^{1}$, Yong Yin ${ }^{1}$, Long D. Nghiem ${ }^{2}$, Xue-Mei Li ${ }^{1 *}$, Mengxi Zhang ${ }^{1}$, Gang Chen ${ }^{1}$, \\ Jianfeng Song ${ }^{1}$, Tao He ${ }^{1^{*}}$ \\ ${ }^{1}$ Laboratory for Membrane Materials and Separation Technology, Shanghai Advanced Research \\ Institute, Chinese Academy of Sciences, Shanghai 201203, China \\ ${ }^{2}$ Strategic Water Infrastructure Laboratory, School of Civil, Mining and Environmental \\ Engineering, University of Wollongong, Wollongong, NSW 2522, Australia
}

Manuscript submitted to Journal of Membrane Science

*Corresponding authors

Phone: 0086-21-20325162, Fax: 0086-21-20325034, email: lixm@sari.ac.cn, het@sari.ac.cn. 


\begin{abstract}
This study demonstrates a sacrificial-layer approach by co-casting, which is the simultaneous casting of two layers, to prepare a polysulfone support (denoted as $\mathrm{PSf}_{\mathrm{co}}$ ) layer with open bottom surface morphology for fabricating thin-film composite forward osmosis (FO) membranes. In the co-casting process, polyetherimide (PEI), used as the sacrificial layer, was co-cast beneath the PSf layer. After the PEI layer was peeled off, $\mathrm{PSf}_{\mathrm{co}}$ was yielded with an open-bottom structure. Results showed that under the same operating condition, the FO membrane prepared by cocasting (denoted as $\mathrm{PSf}_{\mathrm{co}}$-TFC) demonstrated a 10\% higher water flux using $0.5 \mathrm{M} \mathrm{NaCl}$ draw solution and 30\% higher water flux using $4 \mathrm{M} \mathrm{NaCl}$ draw solution in the AL-FS mode in comparison to membranes prepared in a single layer casting technique (denoted as $\mathrm{PSf}_{\mathrm{s}}$-TFC). The $\operatorname{PSf}_{\mathrm{co}}$-TFC exhibits a lower average structural parameter ( $S, 167$ microns) than that of the PSf $_{\mathrm{s}}$-TFC (241 microns), while the water and salt permeability coefficients of both membranes are similar. Results reported here demonstrate that the co-casting technique can be used to fabricate FO membranes with significantly improved performance compared to the conventional approach.
\end{abstract}

Keywords: co-casting; internal concentration polarization; forward osmosis; structural parameter. 


\section{Introduction}

Forward osmosis (FO) is an osmotically driven membrane process, which requires no external hydraulic pressure and has a low membrane fouling propensity [1-3]. In recent years, FO has emerged as an attractive technology for extracting clean water from unconventional sources such as raw sewage [4] and sludge concentrate from anaerobic digestion [5] or treating the flowback frac fluid during shale gas exploration [6-8].

While FO can be potentially resistant to membrane fouling, a major challenge to the practical application of this process is the concentration polarization phenomenon. Both external concentration polarization (ECP) and internal concentration polarization (ICP) exist in the FO process [9-11]. ECP is caused by the slow diffusion of the draw solutes between the bulk solution and the membrane draw solution interface. ECP can be reduced by optimizing the operating conditions such as increasing the cross flow velocity [12] and the solution temperature [13]. On the other hand, ICP is related to the hindered diffusion of the draw solute within the support layer and thus it is an intrinsic property of the membrane and cannot be controlled by optimizing the operating conditions. The structural parameter $(S)$ has been used as an indicative parameter to evaluate the extent of ICP of the FO membrane $[14,15]$. Several approaches have been explored to reduce ICP or the $S$ value, including reducing the thickness support layer [9] and increasing the porosity of the support layer [16-18].

The state of the art FO membrane consists of a polyamide active skin layer on top of a porous polysulfone (PSf) support layer. The structure of the PSf support layer is directly related to the membrane $S$ value. By decreasing the PSf polymer concentration during the preparation of the support layer, a highly porous support layer with large finger-like macro-voids (which result in a small $S$ value) can be formed. However, the low polymer concentration can compromise the 
mechanical strength of the FO membrane. Indeed, a polymer concentration of at least 9 wt.\% is required to ensure adequate structure integrity of the supporting layer [17].

Recent development of the co-casting technique, which was first introduced by He et al., [19], can potentially be another pathway to prepare a mechanically strong support layer but with a low $S$ value. Co-casting involves the simultaneous casting of two layers of different polymer solutions [19-21]. In a recent study, Liu and Ng [22] reported a co-casting technique to prepare a double PSf support layer. The top layer was cast from a high polymer concentration solution while a lower polymer concentration solution was used for the bottom layer. The bottom layer was reinforced by a polyethylene terephthalate mesh to increase the membrane mechanical strength. Liu and $\mathrm{Ng}$ [22] suggested that by having a much more porous layer underneath the normal PSf support layer, the membrane $S$ value could be substantially reduced. It is noteworthy that the top and bottom of the PSf layer are much denser than the finger-like macro-voids in the middle. Thus, another feasible approach is to fabricate a PSf support layer with open structure at the bottom. In this study, we aim to develop a sacrificial co-casting approach by simultaneously forming two layers, then remove the bottom layer to obtain a finger-like macro-void support layer with an open structure at the bottom. The obtained PSf support layer with open finger-like macro-voids was used to prepare thin film composite (TFC) FO membranes performance evaluation.

\section{Materials and methods}

\subsection{Materials and chemicals.}

Polysulfone (PSf P-3500, Solvay), polyetherimide (PEI M1000, GE) was dried at $100{ }^{\circ} \mathrm{C}$ for at least one week before use. Analytical grade N,N-dimethyl acetamide (DMAc), polyethylene 
glycol (PEG400), n-hexane, N-methyl-2-pyrrolidone (NMP), sodium chloride ( $\mathrm{NaCl}$ ) were obtained from Sinopharm Chemical Reagent Co., Ltd. 1,2-Phenylenediamine (MPD, 99\%) and trimesoyl chloride (TMC, 98\%) were from Sigma-Aldrich. Deionized water of conductivity in the range of 8-10 $\mu \mathrm{S} / \mathrm{cm}$ was used in this experiment.

\subsection{Preparation of the support layer.}

PSf/DMAc/PEG400 (18/74/8 wt.\%) and PEI/NMP (17/83 wt.\%) solutions were prepared in a dry glass flask at $65{ }^{\circ} \mathrm{C}$. Solutions were filtered with a $40 \mu \mathrm{m}$ metal filter and de-gassed in an oven at $30{ }^{\circ} \mathrm{C}$ before casting. Two approaches were employed for membrane preparation: single layer casting and co-casting as detailed below. The membranes were cast in the ambient environment at a relative humidity of $30 \%$. PSf solution was spread onto a clean glass plate to form a uniform film using an automatic casting machine (Elcometer 4340, Elcometer Asia Pte Ltd) with a casting knife of $150 \mu \mathrm{m}$. The film was then immersed into a water coagulant bath (30 $\left.{ }^{\circ} \mathrm{C}\right)$. The initial membrane was kept in a water bath to remove residual solvent, rinsed thoroughly and stored in DI water before further usage. Membranes prepared in the single-layer casting process are denoted as PSf $_{\mathrm{s}}$. The co-casting process is schematically shown in Figure 1. PEI/NMP solution was cast first with a knife of $100 \mu \mathrm{m}$ onto a dry, clean glass plate, and the PSf solution was then cast on top of the PEI solution using a $250 \mu \mathrm{m}$ casting knife. The doublelayered film was immersed immediately into a $30{ }^{\circ} \mathrm{C}$ water bath. The PEI layer was manually removed and the remaining PSf layer (denoted as PSf $_{\mathrm{co}}$ ) was rinsed thoroughly and stored in DI water.

\subsection{TFC-FO membrane preparation.}


The polyamide active layer was formed on the top of the PSf support layer [21, 23, 24]. Briefly, the support layer was dried by an air stream and was then immersed in a 2 wt\% MPD aqueous solution for $120 \mathrm{~s}$. The excess MPD solution was removed by air. Subsequently, the membrane was immersed in a $0.15 \mathrm{wt} \% \mathrm{TMC}$ solution in n-hexane for $60 \mathrm{~s}$. After removal of TMC solution, the membrane was left in the ambient condition for $120 \mathrm{~s}$ before further curing in an oven at $100{ }^{\circ} \mathrm{C}$ for $180 \mathrm{~s}$. The final TFC membrane was rinsed thoroughly and stored in DI water for subsequent characterization and experiments.

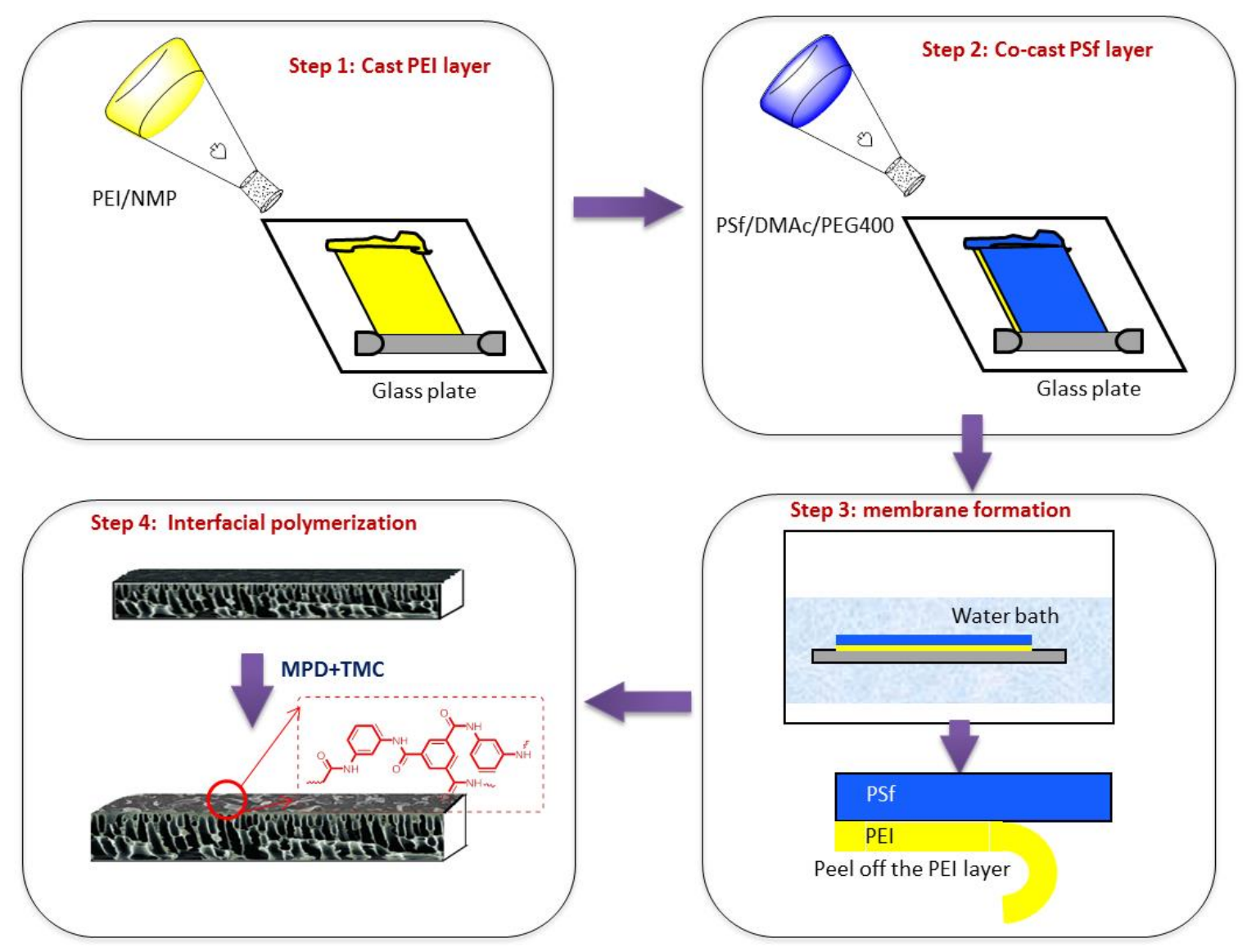

Fig. 1 Schematic illustration of the TFC-FO membrane preparation of the co-cast PSf support layer. Four steps are identified: first, a PEI/NMP solution was cast onto a glass plate (Step 1), and the PSf/DMAc/PEG400 solution was then cast onto the first layer (Step 2); the glass plate 
was immersed in water bath and a two layer film was obtained by delamination of PEI from PSf, and a PSf support was yielded (Step 3); finally a polyamide active layer was formed on the PSf support via interfacial polymerization by applying MPD and TMC solutions sequentially.

\subsection{Characterization of the support membranes}

Pure water permeability (PWP) of the support membranes was determined in a custom made filtration apparatus. All filtration experiments were conducted at 1 bar. The standard deviation of duplicate samples was always lower than $5 \%$.

Porosity $(\varepsilon)$ of the support layer was measured using a previously described technique [25].

First, the membrane was removed from the water bath followed by careful and quick removal of excess water on the surface by absorbent paper and weighed $\left(m_{1}, \mathrm{~g}\right)$. The wet membrane was then freeze-dried overnight. The dry weight membrane was recorded $\left(m_{2}, \mathrm{~g}\right)$. Since the densities of both water $\left(\rho_{w}, 1.00 \mathrm{~g} / \mathrm{cm}^{3}\right)$ and polymers PSf $\left(\rho_{p}, 1.24 \mathrm{~g} / \mathrm{cm}^{3}\right)$ are known, the porosity $\varepsilon$ was calculated as follows [25]:

$$
\varepsilon=\frac{\left(m_{1}-m_{2}\right) / \rho_{w}}{\left(m_{1}-m_{2}\right) / \rho_{w}+m_{2} / \rho_{p}}
$$

Pore size of membrane was measured by capillary flow porometry (Porolux 1000). The samples were first dried in a vacuum oven at $40{ }^{\circ} \mathrm{C}$ for $24 \mathrm{~h}$. Gas permeability of the dry membrane was determined and then the dry membrane was wetted by Porefil (wetting liquid with a low surface tension of $16 \mathrm{dyn} / \mathrm{cm}$ ) and tested under the same condition. The mean pore size of membranes was calculated from wet, dry and half dry conditions. All reported data are average values with standard variation of less than $10 \%$. 


\subsection{Pure water permeability and salt rejection of TFC membranes.}

The intrinsic pure water permeability (A) and solute permeability coefficient (B) of the membranes were determined using a cross-flow RO filtration system (Sterlitech Corporation). The effective membrane area was $42 \mathrm{~cm}^{2}$. The cross-flow rate was $1.5 \mathrm{~L} / \mathrm{min}$ (equivalent to 0.25 $\mathrm{m} / \mathrm{s}$ ) and all filtration experiments were performed at $25{ }^{\circ} \mathrm{C}$. The membrane was pre-pressurized with a feed solution (1000 ppm $\mathrm{NaCl}$ solution) at a pressure $(P)$ of 3.90 bars for about $1 \mathrm{~h}$ before sampling. The standard deviation of above measurements was less than $5 \%$.

The intrinsic pure water permeability (A) was calculated according to:

$$
A=\frac{J_{w}{ }^{R O}}{P}
$$

where $\mathrm{P}$ is the applied trans-membrane pressure and $J_{w}{ }^{R O}$ the permeate water flux.

$\mathrm{NaCl}$ rejection $(\mathrm{R})$ was determined based on the equation below:

$$
R=\left(1-\frac{C_{p}}{C_{f}}\right) \times 100 \%
$$

where $\mathrm{C}_{\mathrm{p}}$ and $\mathrm{C}_{\mathrm{f}}$ represent the $\mathrm{NaCl}$ concentration in the permeate and feed respectively. The salt permeability coefficient $(B)$ was calculated based on the solution-diffusion theory according to Eq. 4 [26-28]:

$$
B=J w \frac{1-R}{R} \exp \left(-\frac{J w}{k}\right)
$$

where $k$ is mass transfer coefficient of the RO test cell, and is determined by 
$k=\frac{S h D}{d h}$

where $D$ is the solute diffusion coefficient, $d_{h}$ is the hydraulic diameter of crossflow cell; $S h$ is the Sherwood number for the appropriate flow regime in a rectangular channel:

$$
\begin{aligned}
& S h=1.85\left(\operatorname{Re} S c \frac{d_{h}}{L}\right)^{0.33} \quad \text { (laminar flow) } \\
& S h=0.04 \operatorname{Re}^{0.75} S c^{0.33} \quad \text { (turbulent flow) }
\end{aligned}
$$

here, $R e$ is the Reynolds number, Sc the Schmidt number, and $L$ is the length of the channel [29, 30] .

\subsection{FO experiments}

The effective area of the FO membrane cell was $30 \mathrm{~cm}^{2}$ (i.e. length, width, and height were 10, 3, and $0.4 \mathrm{~cm}$, respectively). Two variable speed gear pumps were used to circulate the feed and draw solutions co-currently. Flow rates of the feed and draw solutions were monitored with rotameters and kept constant at $1.8 \mathrm{~L} / \mathrm{min}$ (or a flow velocity of $0.25 \mathrm{~m} / \mathrm{s}$ ). The temperature of the feed and draw solutions were maintained at $25^{\circ} \mathrm{C}$. The membranes were tested under the FO mode (which is also known as the AL-FS mode, i.e. the feed solution is in contact with the membrane active layer).

To evaluate the FO performance of the membranes, a $\mathrm{NaCl}$ draw solution $(0.5 \mathrm{M})$ was used in a forward osmosis process with DI water as feed. The change of draw solution concentration was ignored because the ratio of water permeation flux to the volume of the draw solution was less

than $2 \%$ during the FO testing. When using deionized water as the feed, the salt leakage can be 
calculated by measuring the conductivity change in the feed solution and recalculated back to the salt concentration. An electronic balance (CP2002, Ohaus Instrument Co., Ltd.) connected to a computer recorded the weight reduction of the feed solution, which is the volume (or weight) of water permeated into the draw solution, during the FO process. After initial stabilization period of about $10 \mathrm{~min}$, the water flux was taken as the average reading over $1 \mathrm{~h}$. The average of the data for the last half hour was used for calculation. The standard deviation of the data was less than $10 \%$. The FO flux $\left(J_{v}, \mathrm{~L} / \mathrm{m}^{2} . h\right)$ is calculated from the weight change of the feed through

$$
J_{v}=\frac{\Delta m}{S_{m} \cdot \Delta t \cdot \rho_{w}}
$$

where $\Delta m(\mathrm{~g}), \Delta t(\mathrm{~h}), S_{m}, \rho_{\mathrm{w}}$ represent the weight of permeation water collected over a predetermined time, the FO process duration, the effective membrane surface area $\left(\mathrm{m}^{2}\right)$ and the density of water (g/L), respectively.

The reverse salt diffusion or salt leakage, $J_{s}\left(\mathrm{~g} / \mathrm{m}^{2} . \mathrm{h}\right)$, from the draw solution to the feed, is thereafter determined based on the following equation:

$$
J_{s}=\frac{\Delta\left(C_{t} V_{t}\right)}{S_{m} \cdot \Delta t}
$$

where $C_{t}$ and $V_{t}$ are the salt concentration and the volume of the feed solution at time $t$, respectively. $\Delta\left(\mathrm{C}_{\mathrm{t}} \mathrm{V}_{\mathrm{t}}\right)$ is the change of the amount of the salt before and after the test, or the salt diffuse from the draw solution back to the feed.

\subsection{Determination of membrane structural parameter (S)}

In the AL-FS mode, the solute resistivity $K$ can be calculated by the following equation [31]. 


$$
K=\left(\frac{1}{J_{v}}\right) \ln \frac{B+A \Pi_{D . b}}{B+J_{v}+A \Pi_{F, m}}
$$

where $\Pi_{D, b}$ and $\Pi_{F, m}$ represent the osmotic pressure of the bulk draw solution and the osmotic pressure of the feed solution near the membrane surface. $\Pi_{F, m}$ can be calculated according to Eq. 11.

$\frac{\prod_{F, m}}{\prod_{F, b}}=\exp \left(\frac{J_{v}}{k}\right)$

The membrane structural parameter $S$ is a product of the solute resistivity (K) and solute diffusivity (D), and is determined by the membrane tortuosity $\tau$, membrane thickness $t_{s}$, and membrane porosity $\varepsilon$ [31]:

$$
S=K D=\frac{\mathrm{t}_{\mathrm{s}} \tau}{\varepsilon}
$$

\subsection{Scanning Electron Microscopic analysis}

Field-emission scanning electron microscopy (FE-SEM) (S-4800, HITACHI) was used for analyzing the membrane morphology. Wet samples were fractured in liquid nitrogen, dried and then sputter-coated (LFC-1300, JEOL) with a thin layer of gold before SEM imaging.

\section{Results and discussion}

\subsection{Support layers prepared by single layer casting and co-casting}

Fig. 2 shows SEM images of the top surface, cross-section, and the bottom surface of the PSf support layer prepared by co-casting and single layer casting. The $\mathrm{PSf}_{\mathrm{s}}$ and $\mathrm{PSf}_{\mathrm{co}}$ support 
layer membranes have similar top surface which contains round shape pores at $30 \mathrm{~nm}$ or less in diameter (Fig. 2 a,d). This result is expected because the top surfaces were formed under the same condition. According to the phase separation mechanism, as the polymer solution is immersed into the water bath, the exchange of water and solvent occurs at the interface. Immediately at the interface, because of the fast out-flow of solvent, a quick gelation results in a dense kin layer. Further away from the interface, the out-flow of solvent is slow and a porous structure is formed.

As expected, both the support layers of the two types of membranes show sponge like top skin surface and finger-like macro-voids within the internal structure (Figure 2 b,e). However, the thickness of sponge-like stratum at the top surface of the $\mathrm{PSf}_{\text {co }}$ support $(2.2 \mu \mathrm{m})$ is thinner than that of the $\mathrm{PSf}_{\mathrm{s}}$ support $(\sim 9.5 \mu \mathrm{m})$. On the other hand, the depth of the finger-like macrovoid feature of the $\operatorname{PSf}_{\text {co }}$ support layer $(\sim 59 \mu \mathrm{m})$ is larger than that of $\operatorname{PSf}_{\mathrm{s}}(\sim 36 \mu \mathrm{m})$. Morphological difference of the two PSf support layers is most distinctive at the bottom surface: the $\mathrm{PSf}_{\mathrm{s}}$ support has small pores in clusters (Figure 2c) which is in contrast to the large, open pores the $\mathrm{PSf}_{\text {co }}$ support (Figure 2f). In addition, the $\mathrm{PSf}_{\mathrm{s}}$ support is about $47 \mu \mathrm{m}$ in thickness while that of the $\mathrm{PSf}_{\mathrm{co}}$ is $61 \mu \mathrm{m}$ (Figs. 2b,e). Furthermore, porosity of the $\mathrm{PSf}_{\mathrm{co}}$ support (80\%) is higher than that of the $\mathrm{PSf}_{\mathrm{s}}(73 \%)$. As a result, although both support layers have a similar mean pore size, the $\mathrm{PSf}_{\mathrm{co}}$ shows a significantly higher water permeability than the $\mathrm{PSf}_{\mathrm{s}}$. 

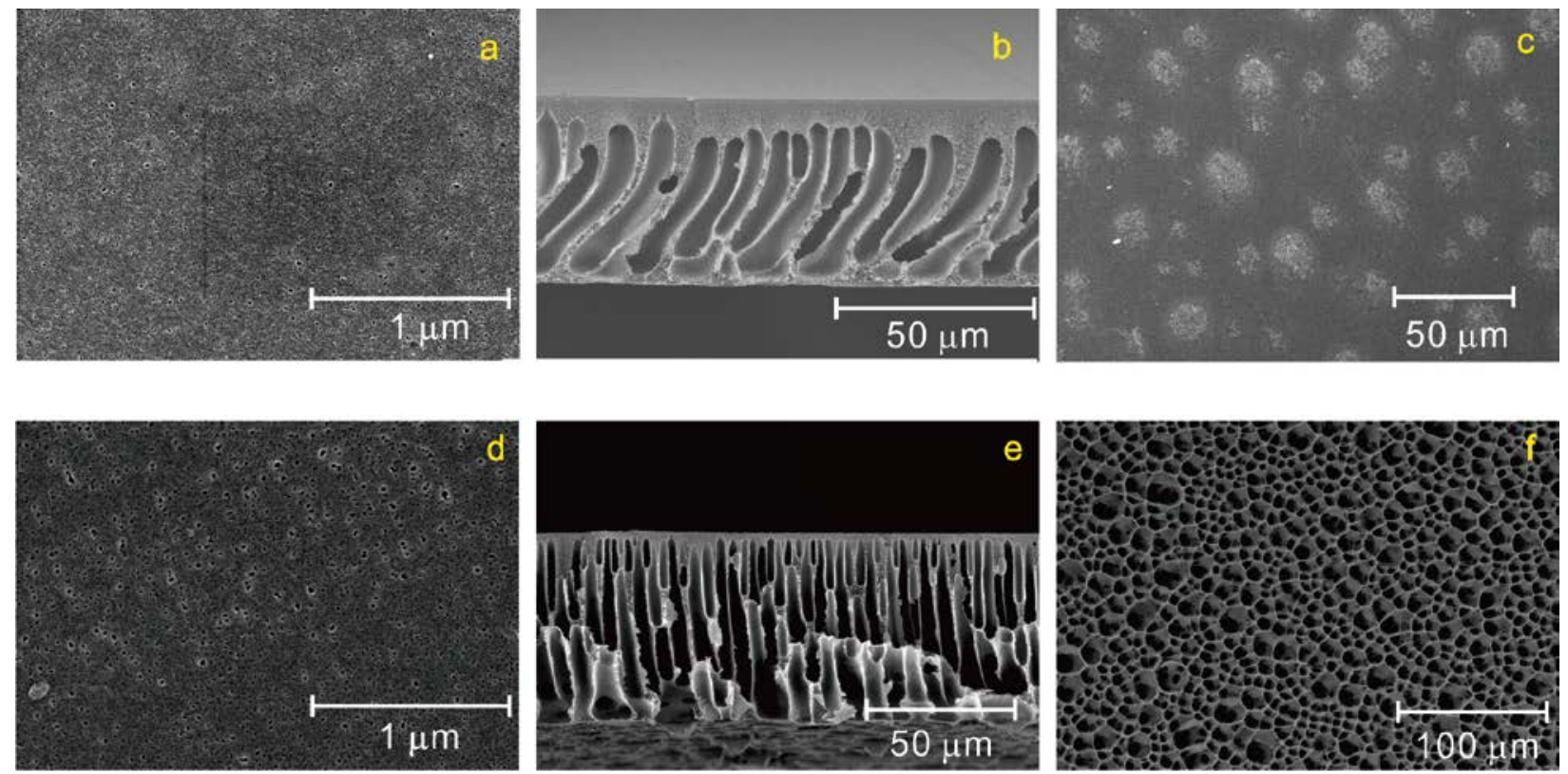

Fig. 2 SEM micrographs of the PSf support layers prepared by single layer casting $\left(\mathrm{PSf}_{\mathrm{s}}\right)$ and cocasting $\left(\mathrm{PSf}_{\mathrm{co}}\right) \cdot(\mathrm{a}),(\mathrm{b})$, and (c) corresponding to top surface, cross section, and bottom surface images of the $\mathrm{PSf}_{\mathrm{s}}$; (d), (e), and (f ) corresponding to top surface, cross section, and bottom surface of the $\mathrm{PSf}_{\mathrm{co}}$ membranes.

Table 1. Properties of $\mathrm{PSf}_{\mathrm{s}}$ and $\mathrm{PSf}_{\mathrm{co}}$ support membranes

\begin{tabular}{lcl}
\hline Properties & $\mathrm{PSf}_{\mathrm{s}}$ & $\mathrm{PSf}_{\mathrm{co}}$ \\
\hline Mean pore size $(\mathrm{nm})$ & 20.2 & 22.1 \\
Pure water permeability $\left(\mathrm{L} / \mathrm{m}^{2}\right.$.h.bar $)$ & 720 & 1020 \\
Porosity $(\%)$ & 73 & 80 \\
Thickness $(\mu \mathrm{m})$ & 47 & 61 \\
\hline
\end{tabular}


The difference in the formation of the finger-like macro-voids in the PSf support layers by the single and co-casting methods is well understood [32-37] and can be described as follows. The phase separation of the PSf solution originates from the interface between the water and the polymer solution due to the inflow of water and the outflow of the solvent. When the water concentration is above the demixing ratio, the liquid-liquid phase separation starts, forming a polymer-rich and polymer-lean phase. As a result, a phase separation frontier is created. Due to the inflow of water and solvent, the polymer-lean phases may grow. The growth of the polymerlean phases requires a large amount of solvent to sustain the increase in the volume. Thus, the direction of the growth of the voids is preferentially towards the direction to the glass plate. In the co-casting process, the PEI layer is underneath the PSf layer, which functions as a solvent reservoir (87\% of NMP in the solution) to the PSf layer. As the phase separation frontier reaches the interface between PSf and PEI layers, this solvent reservoir could provide solvent flow to sustain the growth of the polymer-lean phases in the top PSf layer. The growth of polymer-lean phase results in penetration through macro-void formation at the bottom PSf surface and eventually opens the pores in the bottom surface of the $\mathrm{PSf}_{\text {co }}$ membrane (Fig. 2f). In our previous research [21], when a PEI solution was co-cast on top of a PSf solution, the impact of the growth of the polymer-lean phases was so strong that dented surface was obtained in the bottom surface. The very open bottom surface indicates that there was indeed strong impact as the polymer-lean phases penetrate through the $\mathrm{PSf}_{\mathrm{co}}$ bottom layer [32].

\subsection{Characterization of the TFC-FO membranes}

Application of co-casting technology has shown that addition of an extra polymer solution layer may provide a means to create a new pattern in the membrane morphology. By co-casting 
the PSf onto a PEI layer, the PSf support layer appears to have high water permeability, larger pore size, and higher porosity as well.

Formation of the interfacial polymerization coating layer is based on the reaction of the MPD and TMC at the water/oil interface to form a polyamide layer. Fig. 3 shows the top surface and the skin layer of the TFC membranes prepared on the PSf $\mathrm{s}_{\mathrm{s}}$ and $\mathrm{PSf}_{\mathrm{co}}$ support membranes. Similar ridge-and-valley morphology is observed on both TFC surfaces.
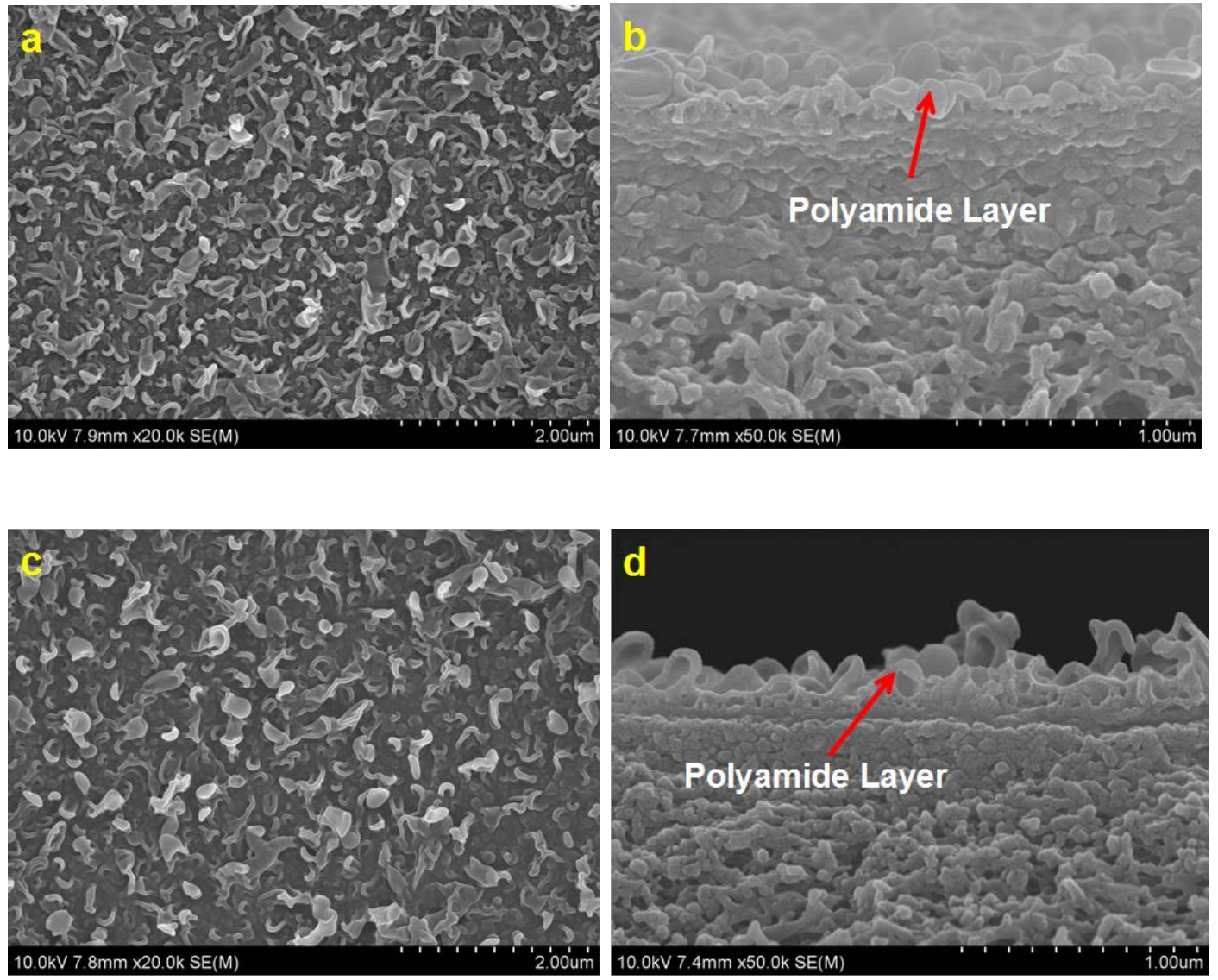

Fig. 3 SEM images of TFC-FO membranes: (a) top surface and (b) cross section of PSf $f_{\mathrm{s}}$-TFC membrane; (c) top surface and (d) cross section of $\mathrm{PSf}_{\mathrm{co}}$-TFC membrane.

For both PSf supports, the preparation of TFC FO membranes were repeated three times and the intrinsic properties of the resulting membranes are shown in Table S1 (supporting 
Information). The average pure water permeability (A) and solute $(\mathrm{NaCl})$ permeability coefficient (B) of the TFC-FO membranes obtained from the PSf $f_{\mathrm{s}}$ and $\mathrm{PSf}_{\mathrm{co}}$ membranes are tabulated in Table 2. The PSf $\mathrm{co}_{\mathrm{co}}$-TFC membrane shows a similar A value $\left(1.65 \mathrm{~L} / \mathrm{m}^{2} \cdot \mathrm{h} \cdot \mathrm{bar}\right)$ as the PSf $_{\mathrm{s}}$-TFC membrane $\left(1.61 \mathrm{~L} / \mathrm{m}^{2} \cdot \mathrm{h} \cdot\right.$ bar). In addition, the solute $(\mathrm{NaCl})$ permeability coefficients (B) of both membranes are also similar. These results are as expected since the active skin layers of the two membranes were prepared using the same method and under the same condition. However, it appeared that the $\mathrm{PSf}_{\mathrm{co}}$-TFC membranes showed in average a lower rejection, which might be due to the thinner top sponge layer that may cause some defects in the interfacial polymerization process. Nevertheless, this rejection is in an acceptable range as compared to literature work as shown in Table 2.

Table 2. Comparison of the TFC-FO membranes synthesized in this study and those from literature

\begin{tabular}{|c|c|c|c|c|c|c|c|}
\hline \multirow[b]{2}{*}{ Sample } & $\begin{array}{l}\text { A } \\
\left(\mathrm{L} / \mathrm{m}^{2} \cdot \mathrm{h} \cdot \mathrm{ba}\right.\end{array}$ & \multirow[b]{2}{*}{$B\left(L / m^{2} \cdot h\right)$} & \multirow[b]{2}{*}{$\mathrm{S}(\mu \mathrm{m})$} & \multirow{2}{*}{$\begin{array}{l}\mathrm{NaCl} \\
\text { rejection } \\
(\%)\end{array}$} & \multicolumn{2}{|c|}{ FO flux $\left(\mathrm{L} / \mathrm{m}^{2} \mathrm{~h}\right) *$} & \multirow[b]{2}{*}{ Reference } \\
\hline & $\begin{array}{l}\left(\mathrm{L} / \mathrm{m}^{2} \cdot \mathrm{h} \cdot \mathrm{ba}\right. \\
\mathrm{r})\end{array}$ & & & & AL-DS & AL-FS & \\
\hline $\mathrm{PSf}_{\mathrm{s}}-\mathrm{TFC}$ & $1.61 \pm 0.03$ & $0.20 \pm 0.11$ & $241 \pm 32$ & $98.5 \pm 0.3$ & $32.5 \pm 3.2$ & $18.1 \pm 1.5$ & This study \\
\hline $\mathrm{PSf}_{\mathrm{co}}-\mathrm{TFC}$ & $1.65 \pm 0.06$ & $0.12 \pm 0.05$ & $167 \pm 16$ & $97.3 \pm 0.9$ & $33.1 \pm 1.4$ & $20.11 \pm 0.9$ & This study \\
\hline HTI-CTA & 0.75 & 0.23 & 393 & 91 & 17 & 8.5 & [10] \\
\hline $\mathrm{PSf}_{9 \%}-\mathrm{TFC}^{\#}$ & $1.9 \pm 0.3$ & $0.33 \pm 0.2$ & $312 \pm 72$ & $98.6 \pm 0.8$ & - & 25 & {$[17]^{\wedge}$} \\
\hline $\mathrm{PSf}_{18 \%}-\mathrm{TFC}^{\#}$ & $0.66 \pm 0.39$ & $0.84 \pm 0.19$ & $\begin{array}{ll}7934 & \pm \\
1051 & \end{array}$ & $96.2 \pm 2.5$ & - & $0.5 \pm 0.1$ & [17] \\
\hline $\mathrm{PSf}_{12 \%}-\mathrm{TFC}^{\#}$ & $1.75 \pm 0.35$ & $0.33 \pm 0.14$ & $502 \pm 59$ & $98.5 \pm 0.3$ & - & $17.6 \pm 0.4$ & [17] \\
\hline PSf-TFC & 1.16 & 0.47 & 492 & 97.4 & - & $18.16^{\wedge}$ & {$[24]$} \\
\hline
\end{tabular}




\begin{tabular}{llllllll}
\hline HTI-CTA & $0.36 \pm 0.11$ & $0.32 \pm 0.11$ & $595 \pm 114$ & $94.4 \pm 0.3$ & - & $9.59 \pm 0.1^{\wedge}$ & [24] \\
\hline PES-TFC & 2.22 & 0.20 & 595 & 91 & 32.2 & 14.0 & {$[21]$} \\
\hline
\end{tabular}

* The FO flux was determined using $0.5 \mathrm{M} \mathrm{NaCl}$ draw solution.

${ }^{\wedge}$ The flux was determined using $1.5 \mathrm{M} \mathrm{NaCl}$ draw solution.

\# Subscript indicates the weight percentage of the PSf concentration during support membrane casting.

Table 2 also shows the performance of the two membranes in AL-DS and AL-FS modes. In the AL-DS mode, both the PSf $\mathrm{s}_{\mathrm{s}}$-TFC and $\mathrm{PSf}_{\mathrm{co}}$-TFC membranes showed similar water flux (in the range of $32.5-33.1 \mathrm{~L} / \mathrm{m}^{2} \cdot \mathrm{h}$ ). This is expected since DI water was used as the feed, and concentrative ICP was negligible. In the AL-FS mode, a water flux of $18.1 \mathrm{~L} / \mathrm{m}^{2} \cdot \mathrm{h}$ was observed for the $\mathrm{PSf}_{\mathrm{s}}$-TFC membrane and $20.1 \mathrm{~L} / \mathrm{m}^{2} \cdot \mathrm{h}$ for $\mathrm{PSf}_{\mathrm{co}}$-TFC membrane. In the AL-FS mode, dilutive ICP is significant because of the water transfer from the feed to the draw solution. Moreover, because dilutive ICP takes place in the porous support, it functions as a stagnant layer which is not disturbed by the hydraulic status of the bulk solution. A higher degree of dilutive ICP would lead to a much lowered effective osmotic pressure difference and thereby causing a lower FO flux [10], which is directly reflected in the flux difference in the AL-FS mode.

Comparison of the structural parameter of the TFC membranes confirmed this premise. The structural parameter of the $\mathrm{PSf}_{\mathrm{co}}$-TFC membrane was $167 \mu \mathrm{m}$, which is considerably smaller than that of the $\mathrm{PSf}_{\mathrm{s}}$-TFC membrane $(241 \mu \mathrm{m})$. Several factors may contribute to the low structure parameter of the $\mathrm{PSf}_{\mathrm{co}}$-TFC membrane: (1) the open bottom surface has a lower transport resistance; (2) relatively thinner porous layer near the skin layer of the PSf membrane; and (3) the higher porosity of the $\mathrm{PSf}_{\mathrm{co}}$ membrane. This lower structural parameter for the $\mathrm{PSf}_{\mathrm{Co}^{-}}$ TFC membranes has indicated that a finger-like structure penetration through to the bottom 
surface is desirable support morphology for FO membranes of low dilutive ICP. The lower solute resistivity $(0.112 \mathrm{~s} / \mu \mathrm{m})$ of the $\mathrm{PSf}_{\mathrm{co}}$-TFC compared to that of $\mathrm{PSf}_{\mathrm{s}}$-TFC $(0.163 \mathrm{~s} / \mu \mathrm{m})$ was a further evidence of co-casting membrane with a lower degree of dilutive ICP. However, the difference in the FO fluxes for two membranes was not significant enough when $0.5 \mathrm{M} \mathrm{NaCl}$ draw solution was used. In the following session draw solutions of higher concentrations in order to further confirm the performance difference of two TFC membranes.

The comparison between our results and the literature values in terms of intrinsic properties and structural parameter is shown in Table 2. For TFC membranes, most literature reported data have shown a rather high structural parameter [17][27-28]. For example, Yip et al. [17] reported that when the PSf concentration in the dope is $18 \mathrm{wt} \%$, after interfacial polymerization, the FO flux is $0.5 \mathrm{~L} / \mathrm{m}^{2} \mathrm{~h}$ with an $S$ value of $7934 \mu \mathrm{m}$. In contrast, at a PSf concentration of $12 \mathrm{wt} \%$, the resulting TFC membrane shows a flux of $17.6 \mathrm{~L} / \mathrm{m}^{2} \mathrm{~h}$ and an $\mathrm{S}$ value of $502 \mu \mathrm{m}[17]$. In our case, the PSf concentration was $18 \mathrm{wt} \%$. However, because of the application of the co-casting process, the $S$ value was much lower than literature reported data.

Based on the present characteristics of both the $\mathrm{PSf}_{\mathrm{s}}$ and $\mathrm{PSf}_{\mathrm{co}}$ support layers (Tables 1 and 2), their tortuosity can be determined. According to Eq. 14, the tortuosity $(\tau)$ values of the PSf $_{\mathrm{s}}$ and PSf $_{\text {co }}$ support layers are 3.9 and 2.2, respectively. The greater tortuosity of the $\mathrm{PSf}_{\mathrm{s}}$ support layer compared to the $\mathrm{PSf}_{\mathrm{co}}$ counterpart could be explained by the difference in their morphology. The finger-like structure in the $\mathrm{PSf}_{\mathrm{co}}$ support layer is significantly larger than the $\mathrm{PSf}_{\mathrm{s}}$ support layer. In addition, the completely open bottom surface of the $\operatorname{PSf}_{\mathrm{co}}$ support layer results in a direct convection pathway. Thinner sponge-like structure near the top skin layer of $\operatorname{PSf}_{\mathrm{co}}$ membrane may also lead to a lower tortuosity pathway.

\subsection{Effects of $\mathrm{NaCl}$ draw solution concentration}


For both the $\mathrm{PSf}_{\mathrm{co}}$-TFC and $\mathrm{PSf}_{\mathrm{s}}$-TFC membranes, water flux increases as the draw $(\mathrm{NaCl})$ solution concentration increase from $0.5 \mathrm{M}$ to $4 \mathrm{M}$ (Fig. 4). This water flux increase can be explained by the increase in osmotic pressure which is the driving force in FO. Nevertheless, it is interesting to note that the water flux increase by the $\mathrm{PSf}_{\mathrm{co}}$-TFC membrane is markedly faster than that by the $\mathrm{PSf}_{\mathrm{s}}$-TFC membrane both in the AL-DS mode and AL-FS mode. In the AL-DS mode, the flux difference between the two TFC membranes was insignificant when $0.5 \mathrm{M} \mathrm{NaCl}$ draw solution was used (Fig. 4A) because the concentrative ICP was expected to be negligible with the use of DI water as feed. But with the increase of draw solution concentration, the flux difference became increasingly significant, and this flux difference was $30 \mathrm{~L} / \mathrm{m}^{2} \mathrm{~h}$ when the $\mathrm{NaCl}$ draw solution concentration was $4 \mathrm{M}$. This flux difference amounts to a $20 \%$ flux reduction using $\mathrm{PSf}_{\mathrm{co}}$-TFC as reference. The reverse solute flux was about $22.5 \mathrm{~g} / \mathrm{m}^{2} \mathrm{~h}$ for the $\mathrm{PSf}_{\mathrm{co}}-\mathrm{TFC}$ membrane at $4 \mathrm{M} \mathrm{NaCl}$ draw solution concentration. In contrast, this value was $24.0 \mathrm{~g} / \mathrm{m}^{2} \mathrm{~h}$ for the $\mathrm{PSf}_{\mathrm{s}}$-TFC membrane. This significant reverse flow of $\mathrm{NaCl}$ has caused an increase in the osmotic pressure in the feed and more importantly the concentrative ICP was also a result. For the both membranes, the operating condition and salt permeation properties were similar, thus the flux difference is ascribed to the different degree of concentrative ICP, due to different structural parameter.

Similarly in the AL-FS mode, at $0.5 \mathrm{M} \mathrm{NaCl}$ draw solution concentration, the water flux of the $\mathrm{PSf}_{\mathrm{co}}$-TFC membrane was only marginally higher than that of the $\mathrm{PSf}_{\mathrm{s}}$-TFC membrane. At $4 \mathrm{M}$ the difference in water flux between the two membranes is $14 \mathrm{~L} / \mathrm{m}^{2} \mathrm{~h}$, which amounts to a $30 \%$ flux reduction using $\mathrm{PSF}_{\mathrm{co}}$-TFC as the reference. Similarly, ECP, dilutive ICP, and salt permeation are the major factors affecting the flux of the FO processes. Because the hydraulic conditions are similar, the difference in the FO flux is ascribed mainly to the difference in 
dilutive ICP and salt permeation properties of the TFC membranes. The smaller S value of $\mathrm{PSf}_{\mathrm{co}^{-}}$ TFC membrane has resulted in a lower degree of dilutive ICP particularly at a high draw solution concentration in comparison to the $\mathrm{PSf}_{\mathrm{s}}$-TFC membrane.

The water flux can also be predicted based on the model developed by Elimelech and coworkers [38, 39]. The flux in the AL-DS mode was calculated according to

$$
J v=A\left\{\frac{\Pi_{D, b} \exp \left(-\frac{J v}{k}\right)-\Pi_{F, b} \exp (J v K)}{1+\frac{B}{J v}\left[\exp (J v K)-\exp \left(-\frac{J v}{k}\right)\right.}\right\}
$$

And the water flux in the AL-FS mode was calculated according to Eq. 14.

$$
J V=A\left\{\frac{\Pi_{D, b} \exp (-J v K)-\Pi_{F, b} \exp (J v / k)}{1+\frac{B}{J V}[\exp (J v / k)-\exp (-J v K)}\right\}
$$

For both membranes, the predicted values closely match the experimental fluxes with variation of less than 5\% both in the AL-DS mode (Fig. 4A) and in the AL-FS mode (Fig. 4B). Very close match of experimental results with theoretical predictions verify that the above analysis was rational. Furthermore, this modeling has confirmed that $\mathrm{PSf}_{\mathrm{co}}$ support layer indeed has a lower tendency for both dilutive ICP (in the AL-FS mode) and concentrative ICP in the AL-DS mode than the single layer $\mathrm{PSf}_{\mathrm{s}}$ support layer. The low structural parameter is considered as the main factor for this performance difference. 

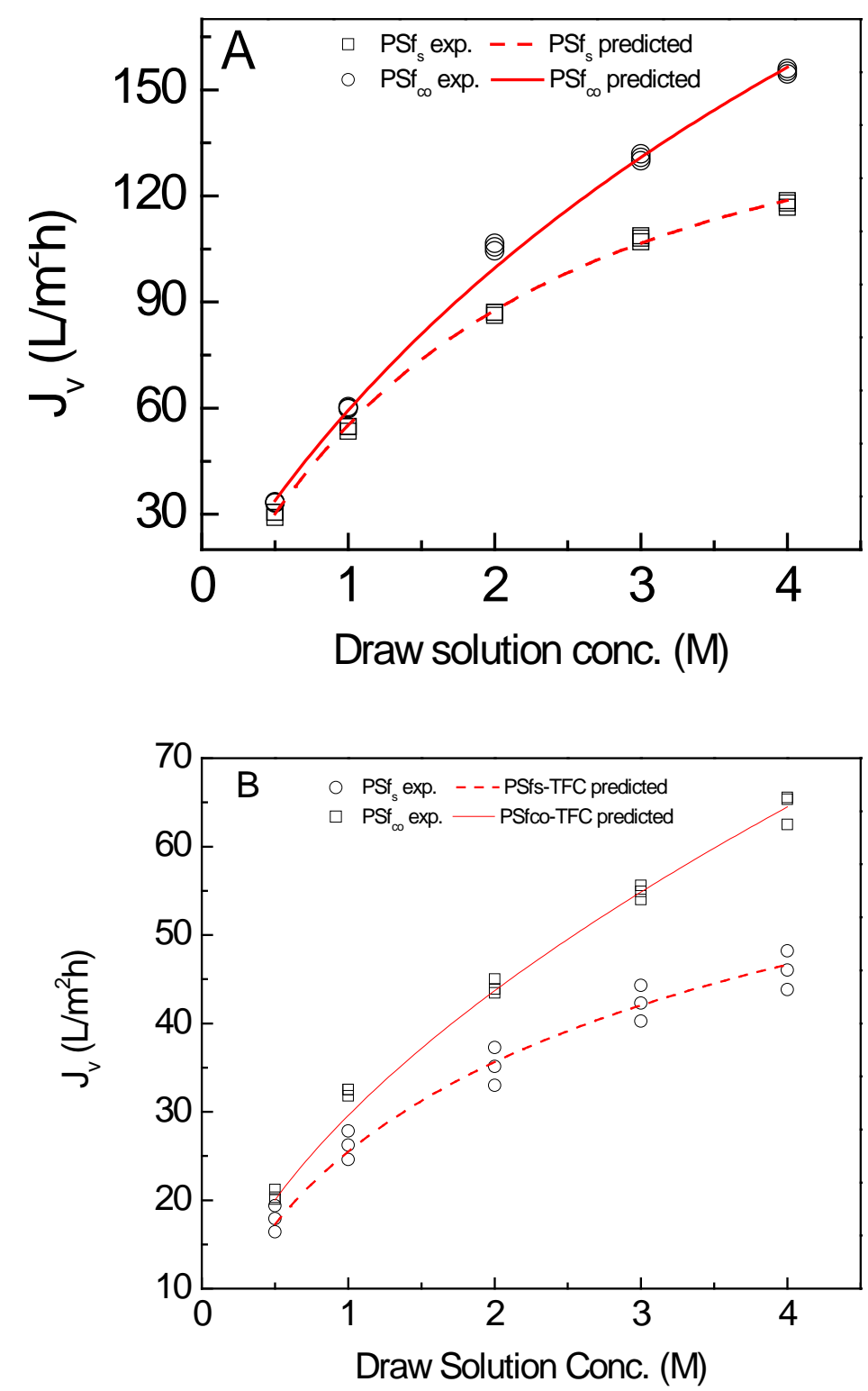

Fig. 4 Water fluxes of TFC-FO membranes as a function of $\mathrm{NaCl}$ draw solution concentration using DI feed water in the AL-DS (A) and AL-FS mode (B). Observed water fluxes are presented as hollow symbols and theoretically predicted fluxes are presented as lines. The flow velocity was $25 \mathrm{~cm} / \mathrm{s}$. The mass transfer coefficient was obtained by fitting the FO flux curves $\left(6.5 \times 10^{-5} \mathrm{~m} / \mathrm{s}\right.$, which is close to literature reported values [38]). 
Reverse flux selectivity of the FO membranes is defined by the ratio between water flux $\left(J_{v}\right)$ and reverse solute flux $\left(J_{s}\right)$, which can be used to evaluate the FO process in terms of draw solute separation. A high $J_{v} / J_{s}$ value is desirable and indicates a low reverse solute flux and high membrane selectivity. The theoretical reverse flux selectivity can be calculated based on the following equation:

$\frac{J_{v}}{J_{s}}=\frac{A n R T}{B}$

where $\mathrm{n}$ is the number of dissolved species created by the draw solute (2 for $\mathrm{NaCl}$ ), $\mathrm{R}$ the ideal gas constant, and $T$ the absolute temperature. The calculated reverse flux selectivity based on Eq. 14 of the PSf - TFC and PSf ${ }_{\text {co }}$-TFC membranes were 7.0 and $8.9 \mathrm{~L} / \mathrm{g}$, respectively, based on Eq. 14. Experimental results revealed a notable deviation from these theoretical values. Indeed, the reverse flux selectivity varied with respect to membrane orientation and decreased as the draw solution concentration increased (Fig. 5). Moreover, variation in the reverse flux selectivity was less significant in the AL-FS mode than in the AL-DS mode for the $\mathrm{PSf}_{\mathrm{s}}$-TFC membrane. For the $\mathrm{PSF}_{\mathrm{co}}$-TFC membrane, at $0.5 \mathrm{M}$ draw solution concentration, the reverse flux selectivity in the AL-DS mode was higher than the theoretically calculated value and that in the AL-FS mode (Fig. $5 B)$. With the increase of draw solution concentration, the reverse flux selectivity dropped from 12.8 L/g to $6.4 \mathrm{~L} / \mathrm{g}$ in the AL-DS mode, in contrast to the relatively more stable reverse flux selectivity in the AL-FS mode $(8.1 \pm 1.6 \mathrm{~L} / \mathrm{g})$. Our results are consistent with a previous study by Zhao et al. [40] who reported different reverse flux selectivity between AL-DS and AL-FS modes. It is noteworthy that the reverse flux selectivity of the $\mathrm{PSf}_{\mathrm{co}}$-TFC membrane was consistently higher than that of the $\mathrm{PSf}_{\mathrm{s}}$-TFC membrane within the draw solution concentration 
range (0.5 - $4 \mathrm{M})$ investigated here in both operation modes (Fig. 5), conclusively confirming the better performance of the $\mathrm{PSf}_{\mathrm{co}}$-TFC membrane
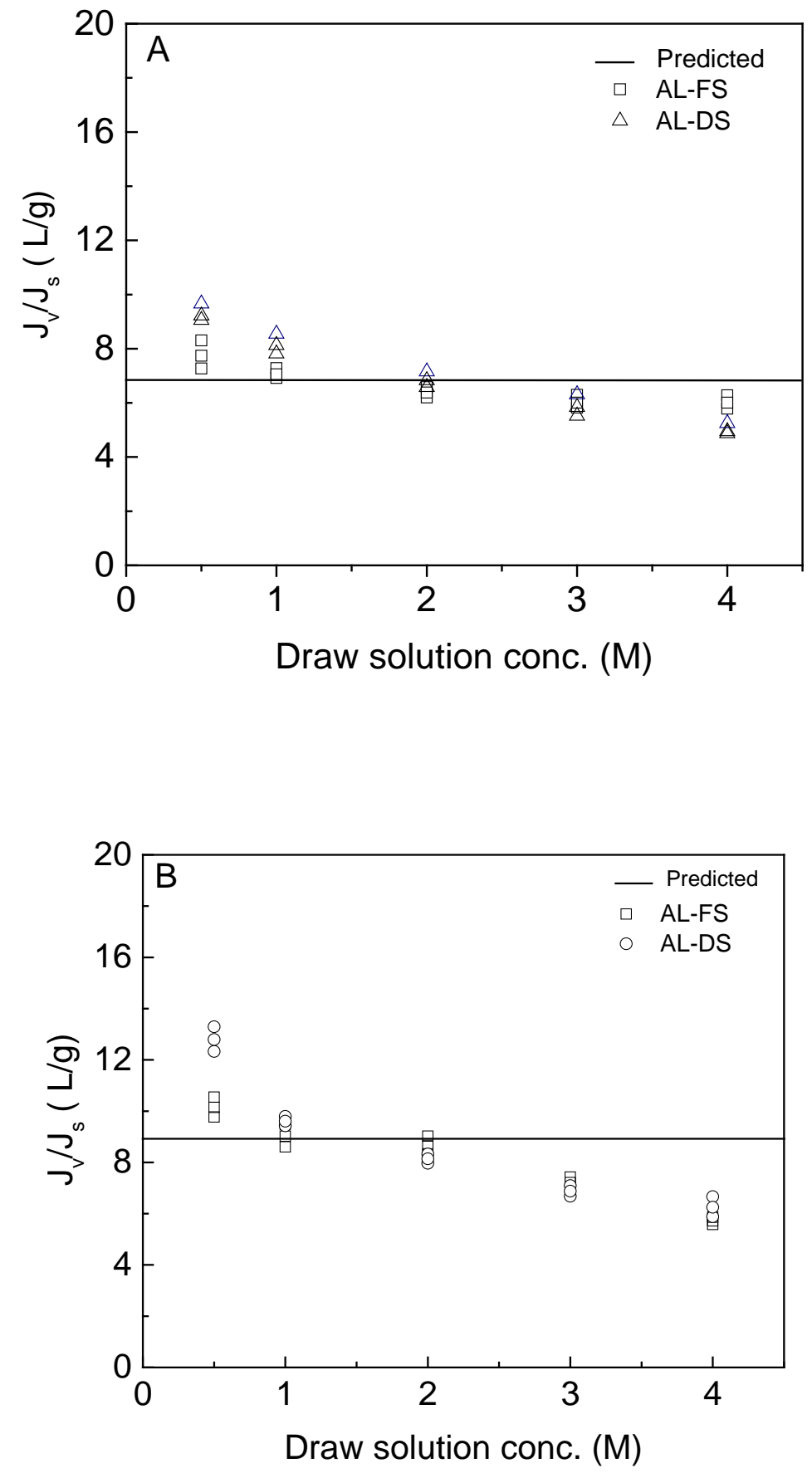
Fig. 5. The reverse flux selectivity the $\operatorname{PSf}_{\mathrm{s}}-\mathrm{TFC}(\mathrm{A})$ and $\operatorname{PSf}_{\mathrm{co}}-\mathrm{TFC}(\mathrm{B})$ membranes as a function of draw solution ( $\mathrm{NaCl}$ ) concentration (DI water was used as the feed).

\section{Conclusions}

A co-casting technique for the preparation of a polysulfone support layer (denoted as PSf $_{\text {co }}$ ) with highly open bottom surface morphology was demonstrated. Characteristics and performance of TFC FO membranes fabricated using the $\mathrm{PSf}_{\text {co }}$ support layer were evaluated and compared to those fabricated using the conventional support layer (denoted as $\mathrm{PSf}_{\mathrm{s}}$ ) obtained from the single layer casting method. The PSf $\mathrm{co}_{\mathrm{co}}$ support layer has open bottom surface structure whereas the $\mathrm{PSf}_{\mathrm{s}}$ support layer has closed bottom surface structure. As a result, the PSf $\mathrm{co}$-TFC membrane has a markedly low structure parameter (S) value compared to the $\mathrm{PSf}_{\mathrm{s}}$-TFC membrane. Although the water permeability (A value) and salt permeability (B value) coefficients of both membranes are similar, the lower $\mathrm{S}$ value of the $\mathrm{PSf}_{\mathrm{co}}-\mathrm{TFC}$ membrane results in a much smaller internal concentration polarization in the AL-FS mode compared to the PSf $_{\mathrm{s}}$ TFC membrane. Indeed, the PSf $\mathrm{co}_{\mathrm{co}}$-TFC membrane produces a considerably higher water flux than the $\mathrm{PSf}_{\mathrm{s}}$-TFC membrane. The improvement in water flux increases as the draw solution concentration increases.

\section{ACKNOWLEDGMENTS}

We acknowledge the financial support from Natural Science Foundation of China (20976083, 21176119), National Key Basic Research Program (973 Program, 2012CB932800) and TMSR from Chinese Academy of Sciences (XDA02020100).

\section{ABBREVIATIONS}




\begin{tabular}{|c|c|}
\hline$A$ & intrinsic pure water permeability $\left(\mathrm{L} / \mathrm{m}^{2} \cdot \mathrm{h} \cdot \mathrm{bar}\right)$ \\
\hline$B$ & salt permeability coefficient $\left(\mathrm{L} / \mathrm{m}^{2} \cdot \mathrm{h}\right)$ \\
\hline$C_{f}$ & feed concentration $(\mathrm{mol} / \mathrm{L})$ \\
\hline$C_{p}$ & permeate concentration $(\mathrm{mol} / \mathrm{L})$ \\
\hline$J_{v}$ & water flux test by $\mathrm{FO}\left(\mathrm{L} / \mathrm{m}^{2} \cdot \mathrm{h}\right)$ \\
\hline$J_{w}$ & water flux test by $\mathrm{RO}\left(\mathrm{L} / \mathrm{m}^{2} \cdot \mathrm{h}\right)$ \\
\hline$J_{s}$ & reverse salt flux by FO $\left(\mathrm{g} / \mathrm{m}^{2} \cdot \mathrm{h}\right)$ \\
\hline K & Solute resistivity $(\mathrm{s} / \mathrm{m})$ \\
\hline$k$ & mass transfer coefficient $(\mathrm{m} / \mathrm{s})$ \\
\hline$D$ & solution diffusion coefficient $\left(\mathrm{cm}^{2} / \mathrm{s}\right)$ \\
\hline$L$ & the length of the channel (m) \\
\hline$\Pi$ & osmotic pressure (bar) \\
\hline$\varepsilon$ & porosity of the membrane \\
\hline$P$ & operation pressure (bar) \\
\hline$S$ & structural parameter $(\mu \mathrm{m})$ \\
\hline$E$ & porosity (\%) \\
\hline & tortuosity \\
\hline
\end{tabular}




\begin{tabular}{|c|c|}
\hline$t_{s}$ & thickness $(\mu \mathrm{m})$ \\
\hline$m_{1}$ & wet membrane weight (g) \\
\hline$m_{2}$ & dry membrane weight (g) \\
\hline$M$ & mass of permeate water (g) \\
\hline$\rho_{w}$ & water density $\left(\mathrm{g} / \mathrm{cm}^{3}\right)$ \\
\hline$\rho_{p}$ & polymer density $\left(\mathrm{g} / \mathrm{cm}^{3}\right)$ \\
\hline$S h$ & Sherwood number \\
\hline$R e$ & Reynolds number \\
\hline Sc & Schmidt number \\
\hline$\Delta t$ & measured time (s) \\
\hline$\Delta m$ & mass of permeability water in FO process (g) \\
\hline$S_{m}$ & effective membrane area $\left(\mathrm{cm}^{2}\right)$ \\
\hline$N$ & the number of dissolved species of draw solution \\
\hline$R$ & ideal gas constant (L.atm.mol ${ }^{-1} \cdot \mathrm{K}^{-1}$ ) \\
\hline$T$ & absolute temperature (K) \\
\hline
\end{tabular}

\section{REFERENCES}


[1] C. Klaysom, T.Y. Cath, T. Depuydt, I.F.J. Vankelecom, Forward and pressure retarded osmosis: potential solutions for global challenges in energy and water supply, Chem. Soc. Rev. , 42 (2013) 6959-6989.

[2] B.D. Coday, B.G.M. Yaffe, P. Xu, T.Y. Cath, Rejection of Trace Organic Compounds by Forward Osmosis Membranes: A Literature Review, Environ. Sci. \& Technol., 48 (2014) 3612-3624.

[3] K. Lutchmiah, A.R.D. Verliefde, K. Roest, L.C. Rietveld, E.R. Cornelissen, Forward osmosis for application in wastewater treatment: A review, Water Res. , 58 (2014) 179-197.

[4] M. Xie, L.D. Nghiem, W.E. Price, M. Elimelech, A Forward Osmosis-Membrane Distillation Hybrid Process for Direct Sewer Mining: System Performance and Limitations, Environ. Sci. \& Technol., 47 (2013) 13486-13493.

[5] M. Xie, L.D. Nghiem, W.E. Price, M. Elimelech, Toward Resource Recovery from Wastewater: Extraction of Phosphorus from Digested Sludge Using a Hybrid Forward Osmosis-Membrane Distillation Process, Environmental Science \& Technology Letters, 1 (2014) 191-195.

[6] X.-M. Li, B. Zhao, Z. Wang, M. Xie, J. Song, L.D. Nghiem, T. He, C. Li, G. Chen, Water reclamation from shale gas drilling flow-back fluid using a novel forward osmosis-vacuum membrane distillation hybrid system, Water Science Technology, (2014) 1036-1044, doi: 1010.2166/wst.2014.1003.

[7] K.L. Hickenbottom, T.Y. Cath, Sustainable operation of membrane distillation for enhancement of mineral recovery from hypersaline solutions, Journal of Membrane Science, 454 (2014) 426-435.

[8] D.L. Shaffer, L.H. Arias Chavez, M. Ben-Sasson, S. Romero-Vargas Castrillon, N.Y. Yip, M. Elimelech, Desalination and Reuse of High-Salinity Shale Gas Produced Water: Drivers, Technologies, and Future Directions, Environ. Sci. Technol. , (2013).

[9] T. Cath, A. Childress, M. Elimelech, Forward osmosis: Principles, applications, and recent developments, Journal of Membrane Science, 281 (2006) 70-87.

[10] J.R. McCutcheon, M. Elimelech, Influence of concentrative and dilutive internal concentration polarization on flux behavior in forward osmosis, J. Membr. Sci. , 284 (2006) 237-247.

[11] S. Zhao, L. Zou, C.Y. Tang, D. Mulcahy, Recent developments in forward osmosis: Opportunities and challenges, Journal of Membrane Science, 396 (2012) 1-21.

[12] K.L. Hickenbottom, N.T. Hancock, N.R. Hutchings, E.W. Appleton, E.G. Beaudry, P. Xu, T.Y. Cath, Forward osmosis treatment of drilling mud and fracturing wastewater from oil and gas operations, Desalination, 312 (2013) 60-66.

[13] S.F. Zhao, L.D. Zou, Effects of working temperature on separation performance, membrane scaling and cleaning in forward osmosis desalination, Desalination, 278 (2011) 157-164.

[14] J. Su, T.-S. Chung, Sublayer structure and reflection coefficient and their effects on concentration polarization and membrane performance in FO processes, J. Membr. Sci. , 376 (2011) 214-224.

[15] J.R. McCutcheon, M. Elimelech, Modeling water flux in forward osmosis: Implications for improved membrane design, AIChE Journal, 53 (2007) 1736-1744.

[16] N. Widjojo, T.-S. Chung, M. Weber, C. Maletzko, V. Warzelhan, A sulfonated polyphenylenesulfone (sPPSU) as the supporting substrate in thin film composite (TFC) membranes with enhanced performance for forward osmosis (FO), Chemical Engineering Journal, 220 (2013) 15-23. 
[17] A. Tiraferri, N.Y. Yip, W.A. Phillip, J.D. Schiffman, M. Elimelech, Relating performance of thin-film composite forward osmosis membranes to support layer formation and structure, J. Membr. Sci. , 367 (2011) 340352.

[18] L. Shi, S.R. Chou, R. Wang, W.X. Fang, C.Y. Tang, A.G. Fane, Effect of substrate structure on the performance of thin-film composite forward osmosis hollow fiber membranes, J. Membr. Sci. , 382 (2011) 116-123.

[19] T. He, M.H.V. Mulder, H. Strathmann, M.Wessling, Preparation of composite hollow fiber membranes: coextrusion of hydrophilic coatings onto porous hydrophobic support structures, Journal of Membrane Science, 207 (2002) 143-156.

[20] Y. Ji, X.-M. Li, Y. Yin, Y.-Y. Zhang, Z.-W. Wang, T. He, Morphological control and cross-flow filtration of microfiltration membranes prepared via a sacrificial-layer approach, J. Membr. Sci. , 353 (2010) 159-168.

[21] X.-M. Li, Y. Ji, Y. Yin, Y.-Y. Zhang, Y. Wang, T. He, Origin of delamination/adhesion in polyetherimide/polysulfone co-cast membranes, J. Membr. Sci. , 352 (2010) 173-179.

[22] X. Liu, H.Y. Ng, Double-blade casting technique for Optimizing substrate membrane in thin-film composite forward osmosis membrane fabrication, Journal of Membrane Science, (2014) http://dx.doi.org/10.1016/j.memsci.2014.1006.1037.

[23] B.-H. Jeong, E.M.V. Hoek, Y. Yan, A. Subramani, X. Huang, G. Hurwitz, A.K. Ghosh, A. Jawor, Interfacial polymerization of thin film nanocomposites: a new concept for reverse osmosis membranes, Journal of Membrane Science, 294 (2007) 1-7.

[24] N.Y. Yip, A. Tiraferri, W.A. Phillip, J.D. Schiffman, M. Elimelech, High Performance Thin-Film Composite Forward Osmosis Membrane, Environ. Sci. Technol. , 44 (2010) 3812-3818.

[25] N. Widjojo, T.-S. Chung, M. Weber, C. Maletzko, V. Warzelhan, The role of sulphonated polymer and macrovoid-free structure in the support layer for thin-film composite (TFC) forward osmosis (FO) membranes, Journal of Membrane Science, 383 (2011) 214-223.

[26] X. Jin, C.Y. Tang, Y. Gu, Q. She, S. Qi, Boric Acid Permeation in Forward Osmosis Membrane Processes: Modeling, Experiments, and Implications, Environ Sci Technol, 45 (2011) 2323-2330.

[27] C.Y. Tang, Q. She, W.C.L. Lay, R. Wang, A.G. Fane, Coupled effects of internal concentration polarization and fouling on flux behavior of forward osmosis membranes during humic acid filtratio, Journal of Membrane Science, 354 (2010) 123-133.

[28] W.W. Phillip, J.S. Yong, M. Elimelech, Reverse Draw Solute Permeation in Forward Osmosis: Modeling and Experiments, Environ. Sci. Technol., (2010).

[29] C.H. Tan, H.Y. Ng, Modified models to predict flux behavior in forward osmosis in consideration of external and internal concentration polarizations, Journal of Membrane Science, 324 (2008) 209-219.

[30] C.H. Tan, H.Y. Ng, Revised external and internal concentration polarization models to improve flux prediction in forward osmosis process, Desalination, 309 (2013) 125-140.

[31] T.Y. Cath, M. Elimelech, J.R. McCutcheon, R.L. McGinnis, A. Achilli, D. Anastasio, A.R. Brady, A.E. Childress, I.V. Farr, N.T. Hancock, J. Lampi, L.D. Nghiem, M. Xie, N.Y. Yip, Standard Methodology for Evaluating Membrane Performance in Osmotically Driven Membrane Processes, Desalination, 312 (2013) 31-38. 
[32] X.-M. Li, T. He, M. Crego-Calama, D.N. Reinhoudt, Conversion of a metastable superhydrophobic surface to an ultraphobic surface, Langmuir, 24 (2008) 8008-8012.

[33] J.G. Wijmans, J.P.B. Baaij, C.A. Smolders, The mechanism of formation of microporous or skinned membranes produced by immersion precipitation, Journal of Membrane Science, 14 (1983) 263-274.

[34] T.-H. Young, L.-W. Chen, Pore formation mechanism of membranes from phase inversion process, Desalination, 103 (1995) 233-247.

[35] P. van de Witte, P.J. Dijkstra, J.W.A. van den Berg, J. Feijen, Phase separation processes in polymer solutions in relation to membrane formation, Journal of Membrane Science, 117 (1996) 1-31.

[36] C.A. Smolders, A.J. Reuvers, R.M. Boom, I.M. Wienk, Microstructures in phase-inversion membranes. Part 1. Formation of macrovoids, J. Membr. Sci. , 73 (1992) 259-275.

[37] I.M. Wienk, R.M. Boom, M.A.M. Beerlage, A.M.W. Bulte, C.A. Smolders, H. Strathmann, Recent advances in the formation of phase inversion membranes made from amorphous or semi-crystalline polymers, J. Membr. Sci. , 113 (1996) 361 - 371.

[38] N.Y. Yip, A. Tiraferri, W.A. Phillip, J.D. Schiffman, L.A. Hoover, Y.C. Kim, M. Elimelech, Thin-Film Composite Pressure Retarded Osmosis Membranes for Sustainable Power Generation from Salinity Gradients, Environ. Sci. \& Technol., 45 (2011) 4360-4369.

[39] A. Tiraferri, N.Y. Yip, A.P. Straub, S.R.V. Castrillon, M. Elimelech, A method for the simultaneous determination of transport and structural parameters of forward osmosis membranes, J. Membr. Sci. , 444 (2013) 523-538.

[40] S. Zhao, L. Zou, D. Mulcahy, Effects of membrane orientation on process performance in forward osmosis applications, J. Membr. Sci. , 382 (2011) 308-315. 